\title{
Seroprevalence of vector borne parasites in naturally exposed dogs of Assam, India
}

\author{
Kanta Bhattacharjee ${ }^{1}$, P. C. Sarmah ${ }^{1}$ and N. N. Barman ${ }^{2}$
}

1. Department of Parasitology, College of Veterinary Science, Assam Agricultural University, Khanapara, Guwahati781022, Assam, India; 2. Department of Microbiology, College of Veterinary Science, Assam Agricultural University, Khanapara, Guwahati-781022, Assam, India

Corresponding author: Kanta Bhattacharjee, email: kantabhatta@gmail.com

Received: 26-12-2013, Revised: 22-01-2014, Accepted: 25-01-2014, Published online: 21-02-2014

doi: $10.14202 /$ vetworld.2014.87-89

How to cite this article: Bhattacharjee B, Sarmah PC and Barman NN (2014) Seroprevalence of vector borne parasites and other infections in naturally exposed dogs of Assam, India, Veterinary World 7(2): 87-89.

\begin{abstract}
Aim: To determine the seroprevalence of vector(tick)-borne Babesia canis, Babesia gibsoni, Ehrlichia canis and Borrelia burgdorferi and mosquito-borne Dirofilaria immitis in naturally exposed pet, working, and street dogs in Assam, India.

Materials and Methods: Seroprevalence of B. canis and B. gibsoni was determined using Indirect Fluorescent Antibody Test (IFAT) kit and for D. immitis, E. canis and B. burgdorferi by Enzyme Linked Immunosorbent Assay (ELISA) in SNAP 3DX kit. The results along with blood microscopy findings were analyzed according to different categories of dogs.

Results: The present study revealed the presence of Babesia canis, Babesia gibsoni, Dirofilaria immitis, and Ehrlichia canis usually in mixed infections. Seropositivity against B. gibsoni and B. canis in IFAT was found comparatively higher in hospital dogs $(84.0 \%$ and $22.0 \%)$ than the street $\operatorname{dogs}(73.3 \%$ and $10 \%)$, whereas evidence of $D$. immitis infection in SNAP 3DX ELISA was found higher in street dogs $(37.5 \%)$ than the hospital group (10\%). Antibody to E. canis was detected in hospital $\operatorname{dogs}(32.0 \%)$ only and none of the dogs was found positive for Borrelia burgdorferi in the same ELISA kit. Besides detection of B. canis, B. gibsoni, D. immitis and E. canis in single or mixed infections, Hepatozoon canis and Anaplasma platys were also recorded in $2.0 \%$ and $8.0 \%$ respectively in hospital dogs and $3.33 \%$ and $6.66 \%$ in street dogs during microscopic examination of blood.
\end{abstract}

Conclusion: High seroprevalence supported by microscopic findings indicate a very strong influence of ticks and mosquitoes as competent vectors in establishing an endemic situation for different species of Babesia, Dirofilaria and Ehrlichia.

Keywords: babesia, dirofilaria, dog, Ehrlichia, IFAT, lyme disease, tick, vector.

\section{I ntroduction}

Dogs are affected by a wide variety of vectorborne pathogens that include various species within the genus Babesia, Hepatozoon, Dirofilaria, Ehrlichia, and Anaplasma, which causes single or mixed infections [1]. Increasing dog population, their trading, and unabated movement within and out of the country have resulted in extension of zoogeographical ranges of vector-borne pathogens for which they are now gaining recognition worldwide [2]. In India sparse information available on vector-borne haemoparasitic diseases of dogs are mainly based on microscopically diagnosed case reports.

The objective of the present study was to determine the seroprevalence of Ehrlichia canis, Babesia canis, Babesia gibsoni, Dirofilaria immitis and of Borrelia burgdorferi, the etiological agent of Lyme borreliosis, in different categories of dogs in Assam.

\section{Materials and Methods}

Study area: The study was conducted in hospital dogs (privately owned pets and working dogs of several

Copyright: The authors. This article is an open access article licensed under the terms of the Creative Commons Attribution License (http://creativecommons.org/licenses/by/2.0) which permits unrestricted use, distribution and reproduction in any medium, provided the work is properly cited. defence organizations) at the Teaching Veterinary Clinical Complex, Assam Agricultural University, Guwahati, and in street dogs at a dog sterilization centre owned by "Just be Friendly", a non-governmental organization under Animal Welfare Board of India.

Ethical approval: The experiments comply with the guidelines laid down by the Institutional Ethical Committee and in accordance with the country law.

Study method: Blood samples, $2 \mathrm{ml}$ each from hospital dogs with clinical problems and from the street dogs were obtained in vials containing EDTA anticoagulant. Antibody activity against $B$. canis and $B$. gibsoni was assessed in plasma of blood samples of 50 hospital dogs by Indirect fluorescent antibody test (IFAT) using B. canis IFA IgG antibody kit and B. gibsoni IFA IgG antibody kit (Fuller Laboratories, USA) as per recommended procedure. IFAT was similarly performed in sera separated from whole blood collected from 30 street dogs for detection of antibodies to $B$. canis and $B$. gibsoni using in-house antigen slides prepared [3] from the blood of a splenectomised bitch which had $10 \%$ parasitaemia with spontaneous $B$. gibsoni, FITC labelled rabbit anticanine conjugate, known $B$. gibsoni and $B$. canis positive and negative control sera.

Enzyme linked immunosorbent assay (ELISA) was performed in whole blood or sera of 50 hospital 
Available at www.veterinaryworld.org/Vol.7/Feb-2014/9.pdf

Table-1. Seroprevalence of Babesia canis and Babesia gibsoni in hospital $(n=50)$ and street $(n=30)$ dogs.

\begin{tabular}{|c|c|c|c|c|c|c|c|c|}
\hline \multirow[t]{3}{*}{ Test } & \multicolumn{4}{|c|}{ Positivity to Babesia gibsoni } & \multicolumn{4}{|c|}{ Positivity to Babesia canis } \\
\hline & \multicolumn{2}{|c|}{ Hospital dog } & \multicolumn{2}{|c|}{ Street dog } & \multicolumn{2}{|c|}{ Hospital dog } & \multicolumn{2}{|c|}{ Street dog } \\
\hline & No. & $(\%)$ & No. & $(\%)$ & No. & $(\%)$ & No. & $(\%)$ \\
\hline $\begin{array}{l}\text { IFAT (1:50 dilution) } \\
\text { Microscopy }\end{array}$ & $\begin{array}{l}42 \\
32\end{array}$ & $\begin{array}{l}(84.0) \\
(64.0)\end{array}$ & $\begin{array}{l}22 \\
14\end{array}$ & $\begin{array}{l}(73.3) \\
(46.6)\end{array}$ & $\begin{array}{l}11 \\
2\end{array}$ & $\begin{array}{l}(22.0) \\
(4.0)\end{array}$ & $\begin{array}{l}3 \\
0\end{array}$ & $\begin{array}{l}(10.0) \\
(0.0)\end{array}$ \\
\hline
\end{tabular}

Table-2. Seroprevalence of Ehrlichia canis, Dirofilaria immitis and Borrelia burgdorferi in hospital $(n=50)$ and street $(n=8)$ dogs.

\begin{tabular}{|c|c|c|c|c|c|c|c|c|c|c|c|c|}
\hline \multirow[t]{3}{*}{ Test } & \multicolumn{4}{|c|}{ Positivity to Ehrlichia canis } & \multicolumn{4}{|c|}{ Positivity to Dirofilaria immitis } & \multicolumn{4}{|c|}{ Positivity to Borrelia burgdorferi } \\
\hline & \multicolumn{2}{|c|}{ Hospital dog } & \multicolumn{2}{|c|}{ Street dog } & \multicolumn{2}{|c|}{ Hospital dog } & \multicolumn{2}{|c|}{ Street dog } & \multicolumn{2}{|c|}{ Hospital dog } & \multicolumn{2}{|c|}{ Street dog } \\
\hline & No. & $(\%)$ & No. & $(\%)$ & No. & $(\%)$ & No. & (\%) & No. & (\%) & No. & (\%) \\
\hline SNAP 3DX & 16 & $(32.0 \%)$ & 0 & $(0.0 \%)$ & 5 & $(10.0 \%)$ & 3 & $(37.5 \%)$ & 0 & $(0.0 \%)$ & 0 & $(0.0 \%)$ \\
\hline Microscopy & 5 & $(10.0 \%)$ & 0 & $(0.0 \%)$ & 2 & $(4.0 \%)$ & 2 & (25.0\%) & - & - & - & - \\
\hline
\end{tabular}

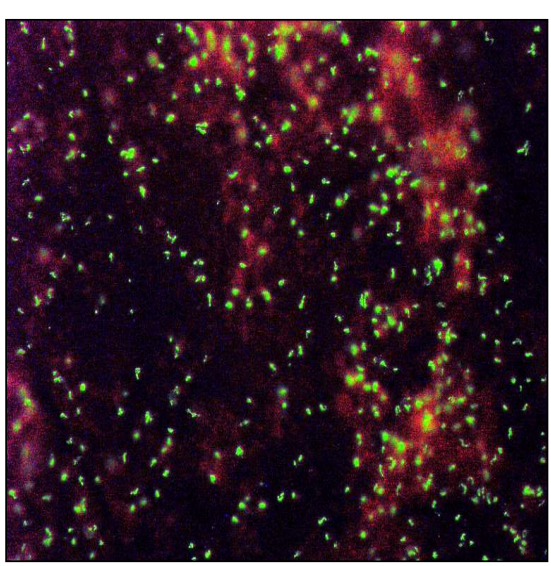

Figure-1. Babesia gibsoni IFAT positive at 1:50 dilution plasma (40X)

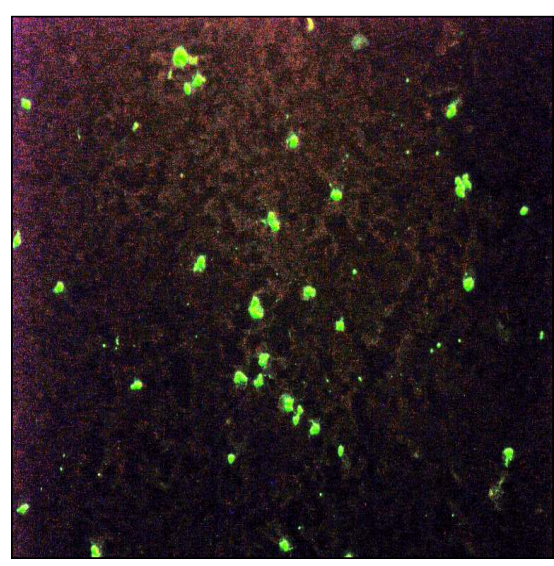

Figure-2. Babesia canis IFAT positive at 1: 50 dilution plasma (40X)

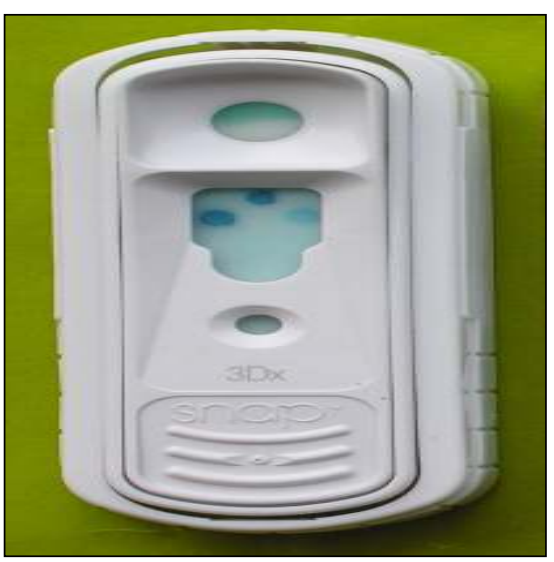

Figure-3. SNAP 3DX test showing $\mathrm{E}$ canis $A b$ and $D$. immitis Ag positive sample dogs and 8 street dogs by SNAP 3DX kit, a commercial product of Idexx Laboratories, USA for simultaneous detection of antibodies to E. canis and B. burgdorferi and $D$. immitis antigen.

Thin blood smears prepared from blood samples of all dogs and stained with Giemsa were microscopically examined for detection of haemoparasites and compared the findings with those of serological tests.

\section{Results}

Results of IFAT and microscopy presented in Table-1 revealed $84.0 \%$ of hospital and $73.3 \%$ of street dogs are seropositive to $B$. gibsoni antibody at 1:50 dilution of test samples (Figure-1), while microscopy could detect $64.0 \%$ in hospital and $46.6 \%$ in street dogs. With respect of B. canis, $22.0 \%$ and $10.0 \%$ of hospital and street dogs, respectively, were antibody positive (Figure-2), while microscopy detected only $4.0 \%$ B. canis in hospital dogs. The street dogs were negative to $B$. Canis with microscopy.

The results of SNAP 3DX test (Figure-3) are presented in Table 2. E. canis antibody was detected in $32.0 \%$ compared to only $10.0 \%$ detection of morula in blood of hospital dogs tested. Street dogs were however found negative to E. canis in both the tests. Evidence of $D$. immitis infection was recorded in both street and hospital dogs. However, street dogs showed higher detection by microscopy (25\%) and SNAP 3DX (37.5\%) than 4-10\% detection in hospital dogs.
Blood samples of dogs in the study population tested by SNAP 3DX were all antibody negative to $B$. burgdorferi.

Among all, IFAT and SNAP 3DX tests conducted simultaneously in 10 microscopically pre-examined blood samples revealed evidence of co-infection with all four parasite species (B. gibsoni, B. canis, D. immitis and E. canis) in a dog, three species (B. gibsoni, B. canis and D. immitis or E. canis) in five dogs and three animals with both the species of Babesia. Additionally, Hepatozoon canis and Anaplasma platys were also detected in blood of $2.0 \%$ and $8.0 \%$ respectively in hospital dogs and $3.33 \%$ and $6.66 \%$ street dogs during microscopic examination.

\section{Discussion}

Higher prevalence of Babesia infection recorded in IFAT than microscopy in both domesticated and street dogs of the present study might suggest subclinical carrier status during which parasitaemia is too low to be detectable by microscopy as opined by Baneth et al and Irwin P.J. [4,5]. Similar results showing high prevalence of Babesia infections have also been recorded by Senthilkumar et al [6].

Better performance of SNAP 3 DX test in diagnosis of canine monocytic ehrlichiosis have been reported by Mircean et al and Ndip et al $[7,8]$ indicating false negative result of microscopic diagnosis in serologi-cally confirmed positive cases. 
In the present study, street dogs showed greater positivity to $D$. immitis than hospital dogs indicating higher risk of exposure to $D$. immitis in outdoor street dogs than the dogs housed indoor as recorded by other workers $[9,10]$. Sensitivity of serological test is higher than that of microscopic diagnosis in the present study, which is in agreement with Sun et al and Bahadori et al $[9,11]$.

Lyme borreliosis in dogs has been reported from United States [12], Europe [13], Africa and Asian countries [4]. In India, occurrence of this zoonotic disease is established among human population [14, 15]. Present investigation conducted in dogs revealed no evidence of disease in dogs although a sizeable number of dogs tested were engaged by the security agencies in the forested area of the North East from where the disease has been reported earlier from human [15].

The present findings on detection of Babesia sp, D. immitis, E. canis, H. Canis, and A. platys bear similarity with previous reports published elsewhere $[2,6]$.

\section{Conclusion}

Serological investigations supported by blood microscopy revealed the prevalence of $B$. gibsoni, $B$. canis, D. immitis, and E. canis usually as mixed infections apart from microscopic detection of $H$. canis and $A$. platys. These findings indicate a very strong influence of the competent vectors in establishing an endemic situation.

\section{Authors' contributions}

KB: Collection of blood samples and photography; KB, PCS: Detailed microscopic examination of blood, serological tests, conception, preparation and revision of the article; NNB: Works relating to IFAT study and photography. All authors read and approved the final manuscript.

\section{Acknowledgements}

The authors are thankful to the Dean, Faculty of Veterinary Science and Director, Post Graduate Studies, Assam Agricultural University, Khanapara, Guwahati for financial assistance provided from the annual grant for post graduate research. Help and facilities rendered by Dr. Sashanka Dutta, Trustee, Just Be Friendly, Guwahati, Dr. Bitupona Deuri and Dr. Lalit Deori to carry out the research are also duly acknowledged.

\section{Competing interests}

The authors declare that they have no competing interests.

\section{References}

1. Megat Abd Rani, P.A., Irwin, P.J., Gatne, M. L., Coleman, G.T. and Traub, R.J. (2010) Canine vector borne diseases in India: A review of literature and identification of existing knowledge gaps. Parasites \& Vectors. 3: 28

2. Shaw, S.E., Day, M.J., Birtles, R.J. and Breitschwerdt, E.B. (2001) Tick-borne infectious diseases of dogs. Trends Parasitol. 17: 74-80.

3. Singh, H., Mishra, A.K., Rao, J.R. and Tewari, A.K. (2007) Seroprevalence of babesiosis in cattle and buffaloes by indirect fluorescent antibody test. J Vet Parasitol. 21: 1-4.

4. Baneth, G., Breitschwerdt, E.B., Hegarty, B.C., Pappalardo, B. and Ryan, J. (1998) A survey of tick-borne bacteria and protozoa in naturally exposed dogs from Israel. Vet. Parasitol. 74: 133-142.

5. Irwin, P.J. (2009) Canine babesiosis: from molecular taxonomy to control. Parasites \& Vectors. 2: S4.

6. Senthil Kumar, K., Vairamuthu, S. and Kathiresan, D. (2009) Prevalence of Haemoprotozoans in Canines in Chennai city. Tamilnadu Journal of Veterinary and Animal Sciences. 5: 104-108.

7. Mircean, V., Dumitrache, M.O., Gyorke, A., Panctchev, N., Jodies, R., Mihalca, A.D. and Cozma, V. (2012) Seroprevalence and geographic distribution of Dirofilaria immitis and tick-borne infections (Anaplasma phagocytophilum, Borrelia burgdorferi sensu lato, and Ehrlichia canis) in dogs from Romania. Vector Borne Zoonotic Dis. 12: 595-604.

8. Ndip, L.M., Ndip, R.N., Esemu, S.N., Dickmu, V.L., Fokam, E.B., Walker, D.H. and McBride, J.W. (2005) Ehrlichial infection in Cameroonian canines by Ehrlichia canis and Ehrlichia ewingii. Vet. Microbiol. 111:59-66.

9. Sun, M., Zhuo, W., Guo, S., Liao, S., Shi, D., Liu, J., Cheng, Z., Liu, Y., Niu, X., Wang, S. and Yang, D. (2012) Serological survey of canine dirofilariasis in Chongqing, Kunming, Nanchang, Fuzhou, Guangzhou, Shenzhen and Nanning in Southern China. Vet Parasitol. 185: 225-228.

10. Melendez, J.A.S., Gonzalez, E.P., Hernandez, B.V.T., Ramos, J.J.Z., Aranda, G.D., Ramirez, R.A., Martinez, M.A.C. and Valdes, V.M.R. (2012) Prevalence of canine Heartworm in Dogs from Monterrey, Mexico. J Anim Vet Adv. 11: 756-759.

11. Bahadori, S.R., Eslami, A. and Bokaic, S. (2007) Evaluation of different methods for diagnosis of Dirofilaria immitis. Pakistan J Biol Sci. 10: 1938-1940.

12. Tzipory, N., Crawford, P.C. and Levy, K.K. (2010) Prevalence of Dirofilaria immitis, Ehrlichia canis and Borrelia burgdorferi in pet dog, racing greyhounds, and shelter dogs in Florida. Vet. Parasitol. 171: 136-139.

13. Welc-Faleciak, R., Rodo, A., Sinski, E. and Bajer, A. (2009) Babesia canis and other tick-borne infections in dogs in Central Poland. Vet. Parasitol. 166: 191-198.

14. Vasudevan, B. and Chatterjee, M. (2013) Lyme borreliosis and skin. Indian J Dermatol . 58: 167-174.

15. Praharaj, A.K., Jetley, S. and Kalghatgi, A.T. (2008) Seroprevalence of Borrelia burgdorferi in North Eastern India. MJAFI. 64: 26-28. 